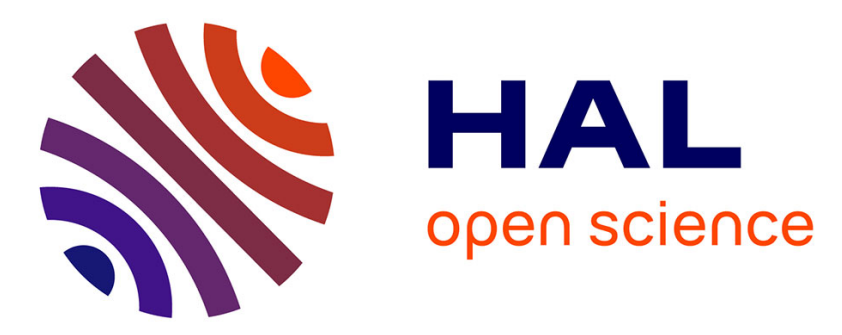

\title{
Boolean analysis of the transcriptomic data to identify novel biomarkers of IVIG response
}

Naresh Rambabu, Mano Joseph Mathew, Srini V Kaveri, Jagadeesh Bayry

\section{To cite this version:}

Naresh Rambabu, Mano Joseph Mathew, Srini V Kaveri, Jagadeesh Bayry. Boolean analysis of the transcriptomic data to identify novel biomarkers of IVIG response. Autoimmunity Reviews, 2021, 20

(7), pp.102850. 10.1016/j.autrev.2021.102850 . hal-03452606

\section{HAL Id: hal-03452606 \\ https://hal.sorbonne-universite.fr/hal-03452606}

Submitted on 27 Nov 2021

HAL is a multi-disciplinary open access archive for the deposit and dissemination of scientific research documents, whether they are published or not. The documents may come from teaching and research institutions in France or abroad, or from public or private research centers.
L'archive ouverte pluridisciplinaire HAL, est destinée au dépôt et à la diffusion de documents scientifiques de niveau recherche, publiés ou non, émanant des établissements d'enseignement et de recherche français ou étrangers, des laboratoires publics ou privés. 
Boolean analysis of the transcriptomic data to identify novel biomarkers of IVIG response

$8{ }^{1}$ Institut National de la Santé et de la Recherche Médicale, Centre de Recherche des Cordeliers,

9 Sorbonne Université, Université de Paris, F-75006 Paris, France

$10{ }^{2}$ École d'ingénieur généraliste en informatique et technologies du numérique, 30- 32 Avenue de

11 la République, F-94800 Villejuif, France

$12{ }^{3}$ Indian Institute of Technology Palakkad, Palakkad, 678623, India

13

$14{ }^{\#}$ These authors contributed equally to this report

*Corresponding author: E-mail address: bayry@iitpkd.ac.in (Jagadeesh Bayry) 


\section{Abstract}

39 inflammatory diseases, but some patients are refractory to IVIG and require alternative

40 treatments. Identifying a biomarker that could segregate IVIG responders from non-responders

41 has been a subject of intense research. Unfortunately, previous transcriptomic studies aimed at

42 addressing IVIG resistance have failed to predict a biomarker that could identify IVIG-non-

43 responders. Therefore, we used a novel data mining technique on the publicly available

44 transcriptomic data of Kawasaki disease (KD) patients treated with IVIG to identify potential

45 biomarkers of IVIG response. By studying the boolean patterns hidden in the expression profiles

46 of KD patients undergoing IVIG therapy, we have identified new metabolic pathways implicated

47 in IVIG resistance in KD. These pathways could be used as biomarkers to segregate IVIG non-

48 responders from responders prior to IVIG infusion. Also, boolean analysis of the transcriptomic

49 data could be further extended to identify a universal biomarker that might predict IVIG response

50 in other autoimmune diseases.

53 Keywords: IVIG, Biomarkers, Autoimmune diseases, Immune metabolism, Therapy,

54 Transcriptome, Boolean patterns 


\section{Highlights:}

57 effects of IVIG are mediated via diverse mechanisms [5, 6].

\section{Introduction}

- Not all autoimmune patients respond to intravenous immunoglobulin (IVIG) immunotherapy.

- Several studies have attempted to identify biomarkers of IVIG response.

- Specificity and/or sensitivity of identified biomarkers of IVIG response are the major issues.

- Boolean analysis of the transcriptomic data could identify novel biomarkers of IVIG response.

- Boolean approach identified several metabolic and signaling pathways implicated in IVIG resistance.

Intravenous Immunoglobulin (IVIG) is a therapeutic normal human Immunoglobulin G (IgG) prepared from the pooled plasma of several thousand healthy donors. Although, initially used in the immunoglobulin (Ig) replacement therapy of primary immunodeficiency (PID) patients, currently high-dose $(1-2 \mathrm{~g} / \mathrm{kg})$ of IVIG is used for the treatment of diverse autoimmune and inflammatory diseases [1]. IVIG is used as a first line therapy in several autoimmune diseases such as Guillain-Barré syndrome (GBS), Chronic inflammatory demyelinating polyneuropathy (CIDP), Idiopathic thrombocytopenia purpura (ITP), Kawasaki disease (KD), 
Autoimmunity stems from the inability of immune system to differentiate self-antigens

86 from the foreign antigens. Mounting aberrant immune response to self-antigens has been linked

87 to over 80 inflammatory disorders, collectively known as autoimmune diseases [7]. IVIG is used

88 as first line therapy for treating several autoimmune diseases. However, not all autoimmune

89 patients respond to IVIG therapy. Resistance to IVIG therapy has been reported in many

90 autoimmune diseases including KD, ITP, CIDP and GBS [8-12].

91

\section{2. Biomarkers of IVIG response}

93 Several studies have attempted to identify biomarkers of IVIG response in various

94 autoimmune diseases. In accordance with the therapeutic use of IVIG in autoimmune and

95 inflammatory diseases, most of these markers followed the trend of either inflammatory cells like

96 platelet, lymphocyte and neutrophil counts or molecules that are the hall marks of inflammation

97 such as alanine aminotransferase, matrix metalloproteinase- 8 C-reactive protein, neutrophil-

98 derived elastase, inflammatory cytokines and chemokines or their receptors (IL-6, IL-1 $\beta$, TNF,

99 G-CSF, CCR2), damage-associated molecular patterns like High mobility group box protein 1

100 (HMGB-1), S100 calcium-binding protein A8 (S100A8), S100A9 [13-19]. However, specificity

101 and/or sensitivity of these markers are the major issues. Even genetic studies on polymorphism

102 (like activating and inhibitory Fc $\gamma$ receptors (Fc $\gamma \mathrm{R})$, Phospholipase A2 Group VII) have been

103 attempted to predict IVIG response [20-22]. But those findings were not reproducible in all the

104 patient groups of given pathology.

105

Majority of the studies on the quest for the biomarkers of IVIG response have been

107 focused on KD patients. KD is an acute systemic vasculitis, which affect children under 5 years 
108 old.

Around

$10910-20 \%$ of KD patients are refractory to IVIG and are at high risk of developing coronary artery

110 aneurysms [10]. Several prediction models such as Kobayashi, Egami, Kawamura, Sano and

111 Formosa have been designed to address IVIG resistance in Japanese KD patients [23-27].

112 However, these models failed to predict IVIG resistance in other ethnicities, and also are not

113 sensitive to predict IVIG resistance in other autoimmune diseases [28].

114

\section{3. DNA Microarrays for the identification molecular biomarkers}

116 One of the classical techniques used to identify molecular biomarker is microarray [29,

117 30], which provides a snapshot of all the biological processes taking place inside a cell. DNA

118 microarray is used to study the transcriptional profiles associated with broad range of diseases to

119 identify disease specific molecular biomarker(s) [31-35]. Unfortunately, the number of

120 microarray datasets available in the public databases to study IVIG response is limited, thereby

121 emphasizing the need to revisit these datasets and seek for hidden patterns using novel data

122 mining techniques.

123

124 Several data analysis techniques are used to understand the biological meaning from the 125 microarray data. Initially, numerical score based gene ranking was used to correlate a gene with 126 a disease, thereby the gene that is highly expressed in a disease is considered to be implicated in 127 then pathogenesis $[36,37]$. Later, an enhanced version of such gene selection technique was used 128 in clustering algorithms to identify huge list of genes exhibiting similar expression levels, 129 comparing the expression levels of such genes with healthy subjects helps us to identify the 130 genes associated with the disease [38]. Nowadays, sophisticated algorithms have been developed 
131 to study complex transcriptional regulatory mechanisms such as co-expression, gene activation,

132 and inhibition using microarray data [39]. Although, the current data mining techniques provide

133 insights into complex gene regulatory mechanism, their ability in predicting biomarker(s), which

134 could segregate IVIG non-responders from responders remain limited.

136 4. Boolean analysis of the transcriptomic data to identify novel biomarkers of IVIG

137 response

138 In this study, we have used a novel boolean approach to segregate IVIG non-responders

139 from responders, and identified that cellular metabolism in peripheral blood mononuclear cells

140 plays a vital role in IVIG resistance. Using the GEO database, the expression profile of the data

141 was extracted and normalized using the quantile method [40]. Log-transformation of the gene

142 expression data was performed. Statistical analysis of gene expression data was based on the

143 single-factor Analysis of variance (ANOVA). Sorted matrix (as a tab-delimited text file) was

144 used for performing the heat map which was generated by selecting gene filtering parameters

145 (FDR threshold $<0.05$ and fold change threshold $=1$ ). Clustering was performed on the sorted

146 matrix using TM4- MEV software (MultiExperiment Viewer, Dan- Farber Cancer Institute,

147 Boston, MA) [41]. Data underwent Z- score normalization so that parameters with vastly

148 different ranges could be compared directly. K-Mean clustering by using Pearson correlation as

149 the distance metric was performed within parameters.

150

To identify the biomarkers that could distinguish IVIG responders from non-responders

152 we studied the boolean behaviors in nearly 40,000 genes. The expression profile of the KD

153 patients undergoing IVIG therapy was extracted from the GEO database (GSE18606). By 
154 converting the microarray readout into 0 's and 1 's $(>0=1 ;<0=0)$, we were able to filter the 155 genes, which exhibit switch like behavior (on/off) specific for the treatment condition (Figure 156 1). Later, we purified these genes that exhibit boolean behavior by manually removing the false 157 positives with the aid of BART [42]. Using this approach, we were able to identify several genes 158 exhibiting boolean behavior specific to IVIG responders and non-responders. Later, we 159 performed enrichment analysis on these genes using EnrichR [43] and identified that cellular 160 metabolism is implicated in IVIG resistance (Table 1).

\section{Boolean approach sheds light on metabolic and signaling pathways specific to IVIG} responders and non-responders

Based on the enrichment analysis, we identified that several metabolic and signaling pathways are implicated in IVIG resistance (Figure 1). We focused our analyses on the

166 pathways that are linked to immune response. Also, to ensure accurate annotation, we selected 167 the pathways with $\mathrm{P}$ values lesser than 0.009. In IVIG non-responders, interferon (IFN) 168 regulatory factor 3 (IRF3)-mediated activation of type 1 IFN was turned on. Genes that increase 169 myeloid cell number, and that promote pyrimidine metabolism, abnormal plasmacytoid dendritic 170 cell physiology were also turned on (Table 1) (Figure 1). Of interest, though several genes

171 (fifteen) were turned on in non-responder patients, these genes contribute to limited set of 172 pathways. On the other hand, genes that modulate lymphocyte migration and Th17 response

173 were switched off (Table 1). Interestingly, the genes that mediate palmitate biosynthesis were 174 also switched off in IVIG non-responders (Table 1). Palmitate is a saturated fatty acid that acts 175 as agonist for Toll-like receptor 4 (TLR4) receptor and promotes inflammation by activating 176 macrophages and innate immune cells [44, 45]. Previous studies have highlighted the importance 
177 of inflammation in IVIG resistance [25]. In IVIG responders, the genes that mediate 178 mitochondrial calcium uptake and several aspects of mitochondria mediated adenosine

179 triphosphate (ATP) production were switched off (Table 1). Interestingly, though the number 180 genes switched off in responder patients with boolean behavior were small (six), these genes 181 contribute to many pathways, particularly mitochondrial functions. The genes that mediate

182 degranulation of mast cells were also switched off (Table 1). This suggest that suppression of 183 mitochondrial function and inflammation plays a vital role in inducing immune homeostasis in 184 IVIG responders.

185

\section{Boolean behavior of genes could not be identified using conventional data analysis}

187 algorithms

There are several tools available to study the differentially expressed genes in a 189 microarray dataset, but they are not developed to specifically study boolean behaviors in a 190 microarray dataset. We performed data analysis on GSE18606 dataset using GEO2R and BART

191 to study whether algorithms developed to study differentially expressed genes in a microarray 192 dataset were able to shed light on boolean behavior, but both GEO2R and BART failed to index 193 the genes exhibiting boolean behavior as differentially expressed. We also used MEV to 194 performed K mean clustering, where we grouped the 40,000 genes into different clusters. We 195 generated 25, 50, 75 and 1000 different clusters to see if clustering algorithm could group the 196 genes that exhibit boolean behavior, but these genes were distributed across different clusters 197 (Table 2).

198

199 7. Conclusion and perspectives 
IVIG is used as first line therapy in several autoimmune and inflammatory diseases, but

201 not all patients respond to IVIG treatment. Identification of biomarker that could segregate IVIG

202 responders from non-responders remains a challenge. Patients who exhibit IVIG resistance need

203 to undergo alternative therapy, thus identifying these patients in the early stages of disease will

204 help clinicians to initiate an alternative treatment strategy. Microarray is a sophisticated

205 technique that sheds lights on the complex processes occurring inside a cell and helps in

206 identifying disease specific biomarkers. There are several software's available to understand the

207 biological meaning hidden in the microarray data, each tool provides insights into the distinct

208 biological processes taking place inside the cell. Despite these advancements in microarray

209 technology, identifying a biomarker, which could segregate IVIG responders from non-

210 responders remains a challenge. In this study we have used a novel data analysis technique,

211 where we screened the genes that exhibit boolean or switch like behavior specific to IVIG

212 responders and non-responders. Using this boolean approach we have identified that cellular

213 metabolism plays a vital role in IVIG resistance. The KD patients who responded to IVIG

214 therapy exhibited limited mitochondrial activity and low inflammation. Whereas, KD patients

215 resistant to IVIG therapy had increased expression of genes that promote inflammation, 216 abnormal regulation of Th17 response.

218 Taking into consideration the role of cellular metabolism in influencing the success of

219 IVIG therapy, diagnostic assays could be developed to rapidly study these parameters in KD

220 patients. This could help clinicians in identifying the IVIG non-responders at an early stage and

221 to initiate alternative therapies to reduce the morbidity and associated therapeutic costs [46].

222 However, the role of cellular metabolism in the outcome of IVIG therapy in other autoimmune 
223 diseases need to be studied to discover a universal biomarker. Currently, dimethyl fumarate, a 224 small molecule targeting glycolytic pathway have been approved to treat multiple sclerosis [47225 49]. Since mitochondria mediated ATP production was suppressed in IVIG responders, small 226 molecules capable of selectively inhibiting mitochondrial function in immune cells could be used 227 along with IVIG to treat IVIG non-responders.

\section{Declaration of Competing Interest :}

233 of action of intravenous immunoglobulin. 


\section{References}

238 [1] Perez EE, Orange JS, Bonilla F, Chinen J, Chinn IK, Dorsey M, et al. Update on the use 239 of immunoglobulin in human disease: A review of evidence. J Allergy Clin Immunol 2017 Mar;139(3S):S1-S46.

241 [2] Gilardin L, Bayry J, Kaveri SV. Intravenous immunoglobulin as clinical immune-

[3] Chaigne B, Rodeia S, Benmostefa N, Bérézné A, Authier J, Cohen P, et al. Corticosteroid-sparing benefit of intravenous immunoglobulin in systemic sclerosisassociated myopathy: A comparative study in 52 patients. Autoimmun Rev 2020

[4] Martínez T, Garcia-Robledo JE, Plata I, Urbano MA, Posso-Osorio I, Rios-Serna LJ, et al. Mechanisms of action and historical facts on the use of intravenous immunoglobulins in systemic lupus erythematosus. Autoimmun Rev 2019 Mar;18(3):279-286.

250 [5] Galeotti C, Kaveri SV, Bayry J. IVIG-mediated effector functions in autoimmune and

[6] Nussinovitch U, Shoenfeld Y. Intravenous immunoglobulin - indications and mechanisms in cardiovascular diseases. Autoimmun Rev 2008 Jun;7(6):445-52..

254 [7] Theofilopoulos AN, Kono DH, Baccala R. The multiple pathways to autoimmunity. Nat 255 Immunol 2017 Jun 20;18(7):716-724

256 [8] Alboudi AM, Sarathchandran P, Geblawi SS, Kayed DM, Inshasi J, Purayil SP, et al. 257 Rescue treatment in patients with poorly responsive Guillain-Barre syndrome. SAGE 258 Open Med 2019 Mar 25;7:2050312119840195. 
259 [9] Heitink-Polle KMJ, Uiterwaal CSPM, Porcelijn L, Tamminga RYJ, Smiers FJ, van 260 Woerden NL, et al. Treatment with intravenous immunoglobulin does not prevent 261 chronic immune thrombocytopenia in children: results of a randomized controlled trial, $262 \quad$ Blood 128 (2016) 866-866.

263 [10] Hwang JY, Lee KY, Rhim JW, Youn YS, Oh JH, Han JW, et al. Assessment of 264 intravenous immunoglobulin non-responders in Kawasaki disease. Arch Dis Child 2011 $265 \quad$ Nov;96(11):1088-90.

266 [11] van Doorn PA, Kuitwaard K, Walgaard C, van Koningsveld R, Ruts L, Jacobs BC. IVIG 267 treatment and prognosis in Guillain-Barré syndrome. J Clin Immunol. 2010 May;30 Suppl 1(Suppl 1):S74-8.

[12] Yoon MS, Chan A, Gold R. Standard and escalating treatment of chronic inflammatory demyelinating polyradiculoneuropathy. Ther Adv Neurol Disord 2011 May;4(3):193200.

[13] Geng Z, Liu J, Hu J, Wang Y, Tao Y, Zheng F et al. Crucial transcripts predict response to initial immunoglobulin treatment in acute Kawasaki disease. Sci Rep 2020 Oct 20;10(1):17860.

[14] Zandstra J, van de Geer A, Tanck MWT, van Stijn-Bringas Dimitriades D, Aarts CEM, Dietz SM, et al. Biomarkers for the Discrimination of Acute Kawasaki Disease From Infections in Childhood. Front Pediatr 2020 Jul 22;8:355.

[15] Wu G, Yue P, Ma F, Zhang Y, Zheng X, Li Y. Neutrophil-to-lymphocyte ratio as a biomarker for predicting the intravenous immunoglobulin-resistant Kawasaki disease. Medicine (Baltimore) 2020 Feb;99(6):e18535. 
281 [16] Galeotti C, Kaveri SV, Bayry J. Molecular and immunological biomarkers to predict IVIg response. Trends Mol Med 2015 Mar;21(3):145-7.

283 [17] Ogihara Y, Ogata S, Nomoto K, Ebato T, Sato K, Kokubo K, et al. Transcriptional

[20] Willemsen SP, Jacobs BC, Huizinga R. Genetic biomarkers for intravenous immunoglobulin response in chronic inflammatory demyelinating polyradiculoneuropathy. Eur J Neurol 2021 Jan 18. doi: 10.1111/ene.14742 (Epub ahead of print).

[21] Gu X, Lin W, Xu Y, Che D, Tan Y, Lu Z, et al. The rs1051931 G>A Polymorphism in the PLA2G7 Gene Confers Resistance to Immunoglobulin Therapy in Kawasaki Disease in a Southern Chinese Population. Front Pediatr 2020 Jun 23;8:338.

[22] Shrestha S, Wiener H, Shendre A, Kaslow RA, Wu J, Olson A, et al. Role of activating Fc $\gamma \mathrm{R}$ gene polymorphisms in Kawasaki disease susceptibility and intravenous immunoglobulin response. Circ Cardiovasc Genet 2012 Jun;5(3):309-16. 
302 [23] Egami K, Muta H, Ishii M, Suda K, Sugahara Y, Iemura M, et al. Prediction of resistance to intravenous immunoglobulin treatment in patients with Kawasaki disease. J Pediatr

[24] Kawamura Y, Takeshita S, Kanai T, Yoshida Y, Nonoyama S. The Combined Usefulness

[25] Kobayashi T, Inoue Y, Takeuchi K, Okada Y, Tamura K, Tomomasa T, et al. Prediction of the Neutrophil-to-Lymphocyte and Platelet-to-Lymphocyte Ratios in Predicting Intravenous Immunoglobulin Resistance with Kawasaki Disease. J Pediatr 2016 Nov; 178:281-284.e1. 2006 Aug;149(2):237-40. of intravenous immunoglobulin unresponsiveness in patients with Kawasaki disease. Circulation 2006 Jun 6;113(22):2606-12.

[26] Lin MT, Chang CH, Sun LC, Liu HM, Chang HW, Chen CA, et al. Risk factors and derived formosa score for intravenous immunoglobulin unresponsiveness in Taiwanese children with Kawasaki disease. J Formos Med Assoc 2016 May;115(5):350-5.

[27] Sano T, Kurotobi S, Matsuzaki K, Yamamoto T, Maki I, Miki K, et al. Prediction of nonresponsiveness to standard high-dose gamma-globulin therapy in patients with acute Kawasaki disease before starting initial treatment. Eur J Pediatr 2007 Feb;166(2):131-7.

[28] Tan XH, Zhang XW, Wang XY, He XQ, Fan C, Lyu TW, et al. A new model for predicting intravenous immunoglobin-resistant Kawasaki disease in Chongqing: a retrospective study on 5277 patients. Sci Rep 2019 Feb 11;9(1):1722.

[29] Sánchez-Peña ML, Isaza CE, Pérez-Morales J, Rodríguez-Padilla C, Castro JM, CabreraRíos M. Identification of potential biomarkers from microarray experiments using 323 multiple criteria optimization. Cancer Med 2013 Apr;2(2):253-65. 
324 [30] Uchida K. Gene expression profiling for biomarker discovery. In: Appasani K., Southern E.M. (eds) Bioarrays. Humana Press. 2007. https://doi.org/10.1007/978-1-59745-3288_7.

[31] Cluzeau CV, Watkins-Chow DE, Fu R, Borate B, Yanjanin N, Dail MK, et al. Microarray expression analysis and identification of serum biomarkers for Niemann-Pick

[32] Cooper CS, Campbell C, Jhavar S. Mechanisms of Disease: biomarkers and molecular

[33] Huang HC, Zheng S, VanBuren V, Zhao Z. Discovering disease-specific biomarker targets from microarray gene expression studies in prostate cancer. Nat Clin Pract Urol 2007 Dec;4(12):677-87. genes for cancer diagnosis and prognosis. Technol Cancer Res Treat 2010 Jun;9(3):21930. One 2013 May 9;8(5):e63249.

344 [37] Zuber V, Strimmer K. Gene ranking and biomarker discovery under correlation. Bioinformatics 2009 Oct 15;25(20):2700-7. 
[38] Wang TN, Li TJ, Shao GF, Wu SX. An improved K-means clustering method for cDNA microarray image segmentation. Genet Mol Res 2015 Jul 14;14(3):7771-81.

[39] Von Mering C, Jensen LJ, Snel B, Hooper SD, Krupp M, Foglierini M, et al. STRING: known and predicted protein-protein associations, integrated and transferred across

[40] Bolstad BM, Irizarry RA, Astrand M, Speed TP. A comparison of normalization methods for high density oligonucleotide array data based on variance and bias. Bioinformatics 2003 Jan 22;19(2):185-93.

[41] Howe E., Holton K., Nair S., Schlauch D., Sinha R., Quackenbush J. MeV: MultiExperiment Viewer. In: Ochs M., Casagrande J., Davuluri R. (eds) Biomedical Informatics for Cancer Research. 2010. Springer, Boston, MA. https://doi.org/10.1007/978-1-4419-5714-6_15

[42] Amaral ML, Erikson GA, Shokhirev MN. BART: bioinformatics array research tool. BMC Bioinformatics 2018 Aug 8;19(1):296.

[43] Chen EY, Tan CM, Kou Y, Duan Q, Wang Z, Meirelles GV, et al. Enrichr: interactive and collaborative HTML5 gene list enrichment analysis tool. BMC Bioinformatics 2013 Apr 15;14:128.

[44] Riera-Borrull M, Cuevas VD, Alonso B, Vega MA, Joven J, Izquierdo E, et al. Palmitate Conditions Macrophages for Enhanced Responses toward Inflammatory Stimuli via JNK Activation. J Immunol 2017 Dec 1;199(11):3858-3869.

[45] Tzeng HT, Chyuan IT, Chen WY. Shaping of Innate Immune Response by Fatty Acid Metabolite Palmitate. Cells 2019 Dec 13;8(12):1633. 
368 [46] Galeotti C, Kaveri SV, Cimaz R, Koné-Paut I, Bayry J. Predisposing factors, 369 pathogenesis and therapeutic intervention of Kawasaki disease. Drug Discov Today 2016 $370 \quad$ Nov;21(11):1850-1857.

371 [47] Angiari S, O'Neill LA. Dimethyl fumarate: targeting glycolysis to treat MS. Cell Res $372 \quad 2018$ Jun;28(6):613-615

373 [48] Kornberg MD, Bhargava P, Kim PM, Putluri V, Snowman AM, Putluri N, et al. 374 Dimethyl fumarate targets GAPDH and aerobic glycolysis to modulate immunity. Science 2018 Apr 27;360(6387):449-453.

376 [49] Montes Diaz G, Hupperts R, Fraussen J, Somers V. Dimethyl fumarate treatment in 377 multiple sclerosis: Recent advances in clinical and immunological studies. Autoimmun $378 \quad$ Rev 2018 Dec;17(12):1240-1250. 
$381 \quad$ Figure Legend

382

383 Figure 1. Genes and the major pathways that exhibit switch like behavior (on/off) in 384 Kawasaki disease patients specific for the IVIG treatment condition. Several genes in IVIG

385 resistant and responder Kawasaki disease patients display switch like behavior (on/off). The 386 cluster number of those genes are highlighted on the right side of the figure. The key pathways 387 that are associated with those genes are also listed.

388

389 

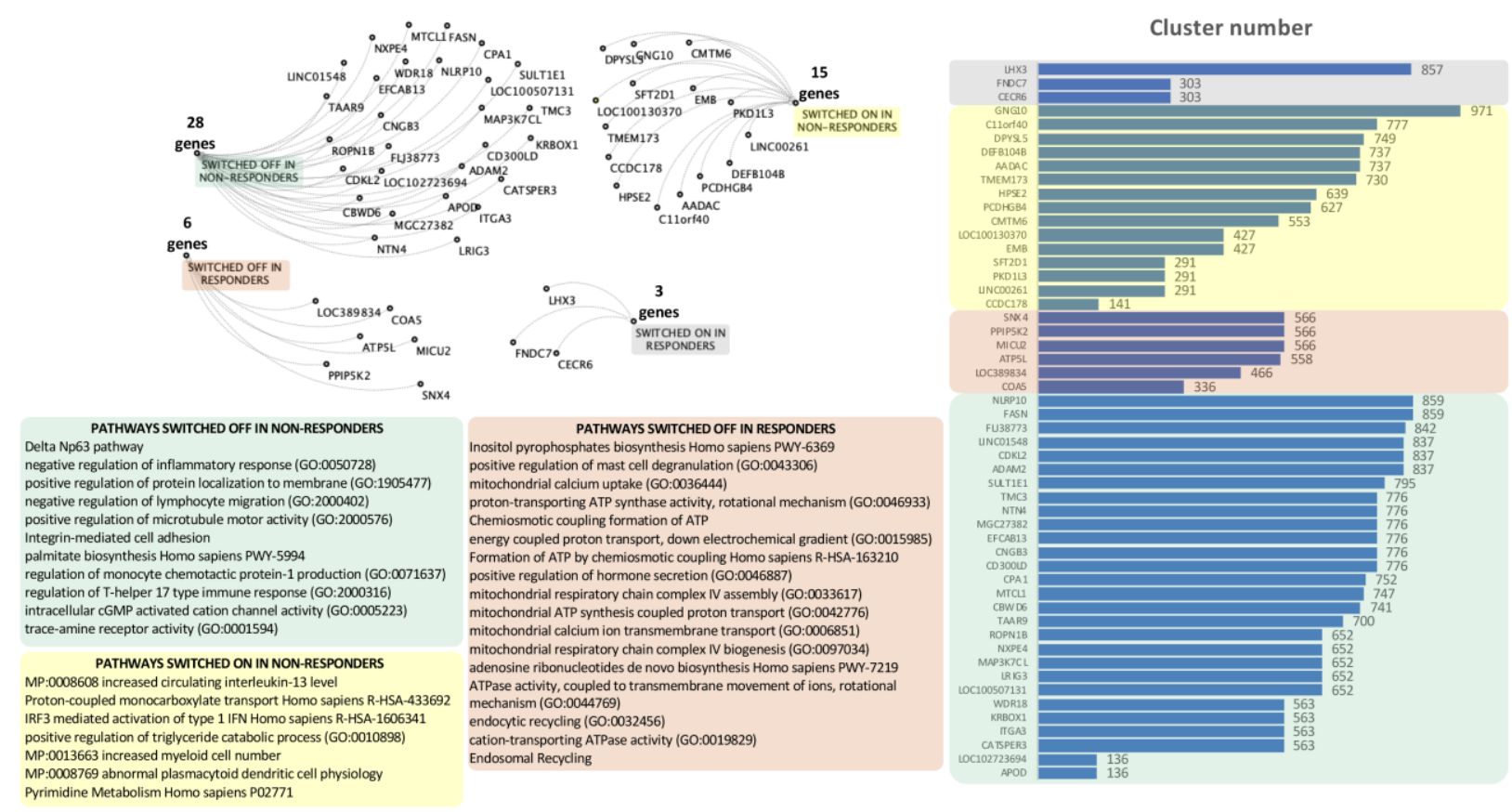

Table 1: Major pathways specific to IVIG responders and non-responders in Kawasaki disease

\section{Main pathways that are switched off in non-responder patients}

\begin{tabular}{llllll}
\hline Name & P-value & $\begin{array}{l}\text { Adjusted } \\
\text { p-value }\end{array}$ & $\begin{array}{l}\text { Odds } \\
\text { Ratio }\end{array}$ & $\begin{array}{l}\text { Combined } \\
\text { score }\end{array}$ & Source \\
\hline Delta Np63 pathway & 0,001965 & 1 & 30,4 & 189,43 & Bioplanet 2019
\end{tabular}

$\begin{array}{llllll}\begin{array}{l}\text { Negative regulation of inflammatory } \\ \text { response (GO:0050728) }\end{array} & 0,005315 & 1 & 18,32 & 95,92 & \text { GO biological process } \\ \end{array}$

$\begin{array}{llllll}\text { Positive regulation of protein } & 0,007787 & 1 & 15,04 & 73,01 & \text { GO biological process } \\ \text { localization to membrane } & & & & 2018\end{array}$

(GO:1905477)

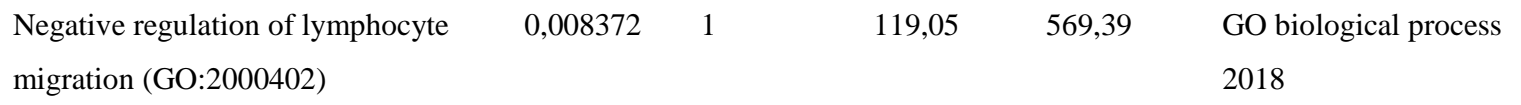


Positive regulation of microtubule

motor activity (GO:2000576)

Integrin-mediated cell adhesion

Palmitate biosynthesis Homo sapiens

PWY-5994

Regulation of monocyte chemotactic

protein-1 production (GO:0071637)

Regulation of T-helper 17 type

immune response (GO:2000316)

Intracellular cGMP activated cation

channel activity (GO:0005223)

Trace-amine receptor activity

(GO:0001594)

400

401

402

403
0,008372

119,05

569,39

GO biological process

2018

$0,00976 \quad 1$

102,04

472,39

HumanCyc 2016

$0,00976 \quad 1$

102,04

472,39

GO biological process

2018

\section{$0,00976 \quad 1$}

102,04

472,39

GO biological process 2018

$0,00976 \quad 1$

102,04

472,39

GO molecular function 2018

0,0097

102,04

472,39

GO molecular function 2018

\section{Key pathways that are switched off in responder patients}

\begin{tabular}{llllll}
\hline Name & P-value & $\begin{array}{l}\text { Adjusted } \\
\text { p-value }\end{array}$ & $\begin{array}{l}\text { Odds } \\
\text { Ratio }\end{array}$ & $\begin{array}{l}\text { Combined } \\
\text { score }\end{array}$ & Source \\
\hline $\begin{array}{l}\text { Inositol pyrophosphates biosynthesis } \\
\text { Homo sapiens PWY-6369 }\end{array}$ & 0,002098 & 0,319 & 476,19 & 2936,47 & HumanCyc 2016 \\
$\begin{array}{l}\text { Positive regulation of mast cell } \\
\text { degranulation (GO:0043306) }\end{array}$ & 0,002098 & 1 & 476,19 & 2936,47 & GO biological process \\
& & & & & 2018 \\
$\begin{array}{l}\text { Mitochondrial calcium uptake } \\
\text { (GO:0036444) }\end{array}$ & 0,002697 & 1 & 370,37 & 2190,93 & $\begin{array}{l}\text { GO biological process } \\
2018\end{array}$ \\
$\begin{array}{l}\text { Proton-transporting ATP synthase } \\
\text { activity, rotational mechanism } \\
\text { (GO:0046933) }\end{array}$ & 0,003296 & 1 & & & \\
\end{tabular}




\begin{tabular}{|c|c|c|c|c|c|}
\hline $\begin{array}{l}\text { Chemiosmotic coupling formation of } \\
\text { ATP }\end{array}$ & 0,003894 & 1 & 256,41 & 1422,64 & Bioplanet 2019 \\
\hline $\begin{array}{l}\text { Energy coupled proton transport, } \\
\text { down electrochemical gradient } \\
\text { (GO:0015985) }\end{array}$ & 0,003894 & 1 & 256,41 & 1422,64 & $\begin{array}{l}\text { GO biological process } \\
2018\end{array}$ \\
\hline $\begin{array}{l}\text { Formation of ATP by chemiosmotic } \\
\text { coupling Homo sapiens R-HSA- } \\
163210\end{array}$ & 0,004791 & 1 & 208,33 & 1112,71 & Reactome 2016 \\
\hline $\begin{array}{l}\text { Positive regulation of hormone } \\
\text { secretion (GO:0046887) }\end{array}$ & 0,00509 & 1 & 196,08 & 1035,4 & $\begin{array}{l}\text { GO biological process } \\
2018\end{array}$ \\
\hline $\begin{array}{l}\text { Mitochondrial respiratory chain } \\
\text { complex IV assembly (GO:0033617) }\end{array}$ & 0,005986 & 1 & 166,67 & 853,06 & $\begin{array}{l}\text { GO biological process } \\
2018\end{array}$ \\
\hline $\begin{array}{l}\text { Mitochondrial ATP synthesis coupled } \\
\text { proton transport (GO:0042776) }\end{array}$ & 0,006284 & 1 & 158,73 & 804,72 & $\begin{array}{l}\text { GO biological process } \\
2018\end{array}$ \\
\hline $\begin{array}{l}\text { Mitochondrial calcium ion } \\
\text { transmembrane transport } \\
\text { (GO:0006851) }\end{array}$ & 0,006284 & 1 & 158,73 & 804,72 & $\begin{array}{l}\text { GO biological process } \\
2018\end{array}$ \\
\hline $\begin{array}{l}\text { Mitochondrial respiratory chain } \\
\text { complex IV biogenesis } \\
\text { (GO:0097034) }\end{array}$ & 0,006284 & 1 & 158,73 & 804,72 & $\begin{array}{l}\text { GO biological process } \\
2018\end{array}$ \\
\hline $\begin{array}{l}\text { Adenosine ribonucleotides de novo } \\
\text { biosynthesis Homo sapiens PWY- } \\
7219\end{array}$ & 0,007477 & 0,5683 & 133,33 & 652,78 & HumanCyc 2017 \\
\hline $\begin{array}{l}\text { ATPase activity, coupled to } \\
\text { transmembrane movement of ions, } \\
\text { rotational mechanism (GO:0044769) }\end{array}$ & 0,007477 & 1 & 133,33 & 652,78 & $\begin{array}{l}\text { GO molecular function } \\
2018\end{array}$ \\
\hline Endocytic recycling (GO:0032456) & 0,008074 & 1 & 123,46 & 594,96 & $\begin{array}{l}\text { GO biological process } \\
2018\end{array}$ \\
\hline $\begin{array}{l}\text { Cation-transporting ATPase activity } \\
\text { (GO:0019829) }\end{array}$ & 0,00867 & 1 & 114,94 & 545,74 & $\begin{array}{l}\text { GO molecular function } \\
2018\end{array}$ \\
\hline Endosomal Recycling & 0,009563 & 1 & 104,17 & 484,36 & $\begin{array}{l}\text { Elsevier pathway } \\
\text { collection }\end{array}$ \\
\hline
\end{tabular}




\begin{tabular}{|c|c|c|c|c|c|}
\hline Name & P-value & $\begin{array}{l}\text { Adjusted } \\
\text { p-value }\end{array}$ & $\begin{array}{l}\text { Odds } \\
\text { Ratio }\end{array}$ & $\begin{array}{l}\text { Combined } \\
\text { score }\end{array}$ & Source \\
\hline $\begin{array}{l}\text { MP:0008608 increased circulating } \\
\text { interleukin-13 level }\end{array}$ & 0,003745 & 1 & 266,67 & 1489,98 & $\begin{array}{l}\text { MGI mammalian } \\
\text { phenotype level } 42019\end{array}$ \\
\hline $\begin{array}{l}\text { Proton-coupled monocarboxylate } \\
\text { transport Homo sapiens R-HSA- } \\
433692\end{array}$ & 0,004492 & 1 & 222,22 & 1201,21 & Reactome 2016 \\
\hline $\begin{array}{l}\text { IRF3 mediated activation of type } 1 \\
\text { IFN Homo sapiens R-HSA-1606341 }\end{array}$ & 0,004492 & 1 & 222,22 & 1201,21 & Reactome 2016 \\
\hline $\begin{array}{l}\text { Positive regulation of triglyceride } \\
\text { catabolic process (GO:0010898) }\end{array}$ & 0,005239 & 1 & 190,48 & 1000,31 & $\begin{array}{l}\text { GO biological process } \\
2018\end{array}$ \\
\hline $\begin{array}{l}\text { MP:0013663 increased myeloid cell } \\
\text { number }\end{array}$ & 0,005985 & 1 & 166,67 & 853,08 & $\begin{array}{l}\text { MGI mammalian } \\
\text { phenotype level } 42019\end{array}$ \\
\hline $\begin{array}{l}\text { MP:0008769 abnormal plasmacytoid } \\
\text { dendritic cell physiology }\end{array}$ & 0,006731 & 1 & 148,15 & 740,89 & $\begin{array}{l}\text { MGI mammalian } \\
\text { phenotype level } 42019\end{array}$ \\
\hline $\begin{array}{l}\text { Pyrimidine Metabolism Homo sapiens } \\
\text { P02771 }\end{array}$ & 0,007476 & 0,8373 & 133,33 & 652,8 & Panther 2016 \\
\hline
\end{tabular}


411 Table 2: General characteristics and parameters of K-Medians Clustering

412

\begin{tabular}{lllll}
\hline Clusters & KMC mode & Iterations & Converged & Pearson Correlation \\
\hline 1000 & Calculated Means & 24 & TRUE & TRUE \\
25 & Calculated Means & 100 & TRUE & TRUE \\
50 & Calculated Means & 69 & TRUE & TRUE \\
75 & Calculated Means & 66 & TRUE & TRUE \\
\hline
\end{tabular}

413

414 